\title{
Causas do desmame precoce e suas interfaces com a condição socioeconômica e escolaridade
}

Recebido em: 06/08/2010

Aceito em: 17/12/2010
Emanuella Freitas Diogo ${ }^{1}$

Taiane Souza ${ }^{2}$

Denise de Azambuja Zocche ${ }^{3}$

\begin{abstract}
Este trabalho visa a analisar as causas do desmame precoce em puérperas que frequentam a Unidade Básica de Saúde no município de Viamão, estado do Rio Grande do Sul, reconhecendo as interfaces da condição socioeconômica e dos fatores culturais implicados. Trata-se de uma pesquisa qualitativa utilizando entrevistas e análise documental. Resultados: a experiência materna e o apoio familiar são fatores relevantes para a manutenção do AME (Aleitamento Materno Exclusivo) e a escolaridade das mães influencia na compreensão das orientações fornecidas pela equipe de saúde.
\end{abstract}

Descritores: Período Pós-Parto, Desmame Precoce, Práticas Culturais, Aleitamento Materno.

\section{Causes of early weaning and its interface with the social-economic status and education}

This study aims to analyze the causes of early weaning among mothers who attend the Basic Health Unit in the municipality of Viamão, the state of Rio Grande do Sul, recognizing the interfaces of socio-economic and cultural factors involved. That is a qualitative research by using interviews and documental analysis. Results: the maternal experience and family support are relevant factors to the maintenance of EBF (exclusive breastfeeding), and maternal schooling influences the understanding of the guidelines provided by the health team.

Descriptors: Postpartum Period, Early Weaning, Cultural Practices, Breastfeeding.

\section{Las causas de destete precoz y sus interfaces con la situación socio-económica y la educación}

Este estudio tiene como objetivo examinar las causas de destete precoz entre las madres que asisten a la Unidad Básica de Salud en el municipio de Viamão el estado de Rio Grande do Sul, el reconocimiento de las interfaces de los factores socioeconómicos y culturales involucrados. Se trata de una investigación cualitativa utilizando entrevistas y análisis de documentos. Resultados: la experiencia derivada de la maternidad y el apoyo familiar son factores relevantes para el mantenimiento de la LME (lactancia materna exclusiva), y la escolaridad de la madre influye en la comprensión de las orientaciones dadas por el equipo de salud.

Descriptores: Periodo postparto, Destete precoz, Las prácticas culturales, La lactancia materna.

\section{INTRODUÇÃO}

A pesar do aumento das taxas de amamentação na maioria dos países nas últimas décadas, inclusive no Brasil, a tendência ao desmame precoce continua e o número de crianças amamentadas segundo as recomendações da Organização Mundial da Saúde (OMS) ainda é pequeno(1). O desmame precoce é a interrupção do aleitamento materno ao peito antes de o lactente ter completado seis meses de vida, independentemente de a decisão ser da mãe ou não e do motivo da interrupção(2). As crenças e as práticas culturais influenciam significativamente nos métodos de alimentação infantil. Embora haja regras culturais reconhecidas, não se pode assumir que as observações gerais sobre um grupo cultural sejam verdadeiras para todos os seus membros. A
Política de Incentivo ao Aleitamento Materno ${ }^{(3)}$ aborda, entre tantas atividades, as orientações relacionadas à promoção, proteção e apoio ao aleitamento materno. Porém, mesmo após orientações recebidas por profissionais da área da saúde, as mães seguem apresentando baixa adesão ao aleitamento materno exclusivo.

A participação da mulher dentro da sociedade capitalista contribui grandemente para o abandono da amamentação. Muitas mães que utilizam o trabalho informal se veem obrigadas a retornar ao serviço por não terem carteira assinada com direito aos benefícios trabalhistas ${ }^{(4)}$. Portanto, essas puérperas necessitam trabalhar, o que as impossibilita de manter o AME. Sendo assim, o desmame precoce é um problema de saúde que tem uma implicação 
não só biológica, mas social, já que tem repercussões na qualidade e expectativa de vida dos recém-nascidos, pois o desmame precoce está relacionado, entre outras causas, à mortalidade infantil.

No Brasil, é preconizado o aleitamento materno exclusivo durante os primeiros seis meses de vida, pressupondo-se que a criança receba apenas o leite materno, sem adição de água, chás, sucos e outros líquidos ou sólidos, exceto gotas ou xaropes de vitaminas, suplementos minerais ou outros medicamentos ${ }^{(5)}$. Embora essa recomendação seja abordada no pré-natal e no puerpério imediato, e ainda nas campanhas midiáticas, a decisão de amamentar está interligada à história de vida de cada mãe e ao significado que se atribui a esse ato. Dessa forma, tal opção pode ser influenciada pelo aspecto emocional, social, cultural e econômico da mãe. Trata-se de uma questão de assumir riscos, sendo determinada pelas interações que ocorrem durante essa experiência vivida pela mulher ${ }^{(6)}$.

Múltiplos são os fatores que levam as mulheres, os profissionais da área da saúde e a população a marginalizar o leite humano - entre eles tabus, mudanças sociais e desinformação. Muitos não sabem da importância que o leite humano tem, e, menos ainda, dos riscos que as crianças estão sujeitas ao serem alimentadas com leite artificial. Estudos mostram que uma boa orientação sobre a técnica adequada de amamentação no período pré e pós-gestacional pode reduzir a incidência de mulheres que relatam baixa produção de leite. Além disso, a pega inadequada poderá gerar lesões mamilares, causando dor e desconforto para a mãe, o que pode comprometer a continuidade do aleitamento, caso não seja devidamente corrigida a forma de amamentar ${ }^{(7)}$.

Outro fator relevante é conciliar trabalho e amamentação, pois a participação da mulher na força de trabalho tem sido relatada como causa para o desmame precoce, mesmo em países que têm uma legislação protetora da mulher, mas que, como no Brasil, é pouco cumprida. Não basta a mãe ser informada das vantagens do aleitamento materno e optar por essa prática, mas sim ser inserida em um ambiente favorável à amamentação e contar com o apoio de profissionais habilitados para ajudá-la, se necessário. No entanto, nem sempre o profissional de saúde tem conhecimentos e habilidades suficientes para manejar adequadamente as inúmeras situações que podem servir de obstáculo à amamentação bem-sucedida. Para atender a essas necessidades, acreditamos que as práticas de educação são dispositivos que podem potencializar o $A M E$, o que se constitui num desafio, pois é complexo atuar junto a essas mulheres na tentativa de intervir nos aspectos obscuros que levam à decisão materna de desmame e introdução de outros alimentos na dieta do recém-nascido(8). A educação em saúde parte de uma concepção de saúde ampliada e de uma pedagogia problematizadora. Portanto, o profissional de saúde que se relaciona com a mãe durante o ciclo gravídico-puerperal tem importante função nos programas de saúde durante o pré-natal, devendo preparar a gestante para o aleitamento, para que, no pós-parto, o processo de adaptação da puérpera ao aleitamento seja facilitado e tranquilo, evitando, assim, dúvidas, dificuldades e possíveis complicações $^{(9,3)}$. Frente ao exposto, analisamos quais as razões que levam as mães que utilizam o serviço de saúde municipal a realizarem o desmame precoce de seus filhos.

\section{METODOLOGIA}

Trata-se de um estudo com abordagem qualitativa, descritiva e exploratória que visou a analisar as causas do desmame precoce em puérperas que frequentam a unidade básica de saúde no município de Viamão, no estado do Rio Grande do Sul, reconhecendo as interfaces da condição socioeconômica e dos fatores culturais implicados nos sujeitos de pesquisa; oito puérperas, maiores de 18 anos, que utilizavam o serviço desaúdee que estavam com dificuldades de manter o aleitamento materno exclusivo. Este estudo foi aprovado pelo Comitê de Ética em pesquisa do Centro Universitário Metodista do IPA e da Secretaria de Saúde de Viamão. A coleta de dados foi realizada por entrevista e análise documental dos prontuários das entrevistadas, a fim de caracterizar a amostra e compreender seu contexto social no período de agosto a setembro de 2009. Para a análise das entrevistas, utilizou-se o estudo de conteúdo(10), de onde emergiram duas categorias: manutenção do aleitamento materno: o saber e o aprender; e amamentação: seus limites, que inclui mais duas subcategorias: saberes e o aprender a amamentar; e as interrupções do aleitamento materno: entre a impossibilidade e a vontade.

\section{ANÁLISE DOS DADOS}

Muitos fatores contribuem para o desmame precoce. No entanto, a falta de conhecimento sobre aleitamento materno por parte das mães tem papel importante na redução da duração dessa prática ${ }^{(12)}$. As orientações recebidas pelas mulheres no alojamento conjunto foram fundamentais para o estabelecimento da amamentação.

"Recebi orientação sobre amamentação aqui mesmo no clubinho do bebê, com a técnica de enfermagem... e aí ela me ensinou, eles me explicaram tudo direitinho". (E1)

Todas as entrevistadas citaram o hospital como o serviço que lhes "ensinou" a amamentar.

"...é que lá no hospital eles me ensinaram, aprendi com as enfermeiras, amamento assim porque aprendi no hospital". (E7)

Toda mulher, diante da crença de que é capaz de vivenciar 
a experiência da amamentação com sucesso, estará preparada para exercê-la a partir do conhecimento dos aspectos básicos e práticos da amamentação ${ }^{(8)}$.

\section{Apoio, vontades e limites}

A decisão materna de amamentar ou não e por quanto tempo é regida por múltiplos componentes, tais como: motivação, apoio familiar e cultural, educação pré e pósnatal e conhecimentos e habilidades específicos sobre como amamentar ${ }^{(12)}$. Constata-se a relevância dos fatores sociais e culturais nesta fala:

"Aprendi a amamentar o meu primeiro filho com a minha mãe". (E2)

Durante as entrevistas, constatamos a influência da avó materna na prática de amamentar; ao transmitir conhecimentos e sua cultura, é valorizada e respeitada por sua experiência e vivência.

"Já tive experiência com amamentação. Amamentei anteriormente. Aprendi com a minha mãe." (E4)

Ainda sobre o apoio familiar e a experiência de outras mulheres, a puérpera desenvolve autoconfiança e sente-se mais segura para realizar o aleitamento, conforme relato:

“...Não tive experiência com amamentação; tive dificuldade de amamentar no primeiro dia, porque ela não queria mamar. Ela só queria dormir, aí a gente começou a forçar, a forçar... Ah, ela pegava, daí machucou bastante, mas mesmo assim eu continuei dando, mesmo doendo eu dava. Ah, agora ela mama bem até demais. Aprendi a amamentar com a minha família, pois eu também tenho uma cunhada que estava amamentando...". (E8)

Além do fator cultural, percebemos que as mães que receberam orientações no hospital ficaram muito satisfeitas, mas ainda o que mais as motivava era a presença de outra mulher (mãe) que a auxiliava durante o pós-parto.

"Já amamentei anteriormente. Normalmente, eu amamento até 2 anos... porque eu estou trabalhando, né... desde os 4 meses, mas eu não tiro o peito. A minha mãe também ajudou muito lá no hospital." (E3)

"...eu aprendi com o pessoal lá no hospital..." (E6)

\section{Interrupções do aleitamento materno:} entre a impossibilidade e a vontade

A literatura tem nos apontado sobre a importância da técnica de amamentação e que a maior parte das dificuldades de aleitamento está vinculada à pega inadequada no que diz respeito à sucção. Muitas mães relatam que mamilos sensíveis e a presença de fissuras em suas mamas dificultam no aleitamento materno exclusivo, sendo difícil para elas permanecer amamentando com dor.

"Tive dificuldade no início, ela machucou... e aí eu tive de dar NAM para ela, porque criou fissuras." (E7)
Percebemos, nessa fala, um dos motivos que levam mulheres a deixar de amamentar seus filhos (traumas mamilares e dor), o que acaba na introdução de complemento para repor o leite materno. Como consequência, a mãe pode introduzir precocemente outros alimentos, contribuindo, assim, para o desmame precoce ${ }^{(7)}$.

Observou-se que a maioria das mães possuía o primeiro grau incompleto, fator que causa preocupação, considerandose que a baixa escolaridade é determinante para a prática e continuidade da amamentação(11). No que se refere ao grau de instrução materna, muitos estudos têm demonstrado que esse fator afeta a motivação para amamentar.

"Amamentei até os 6 meses com leite do peito, e agora ele já está comendo papinha, mas continua mamando." (E1)

Nessa fala, quando questionada se realiza aleitamento materno exclusivo, a mãe relatou que sim. Porém, identificamos uma contradição, pois o bebê de 6 meses recebe outra fonte alimentar além do leite materno, indicando que as orientações sobre AME não foram bem compreendidas pela mulher todas dizem dar exclusivamente leite materno e, no entanto, oferecem outros tipos de alimentos. Atualmente, a prática do aleitamento materno está sendo retomada, com o intuito de aumentar a prevalência da amamentação exclusiva até o sexto mês, momento em que devem ser introduzidos outros alimentos complementares na dieta da criança. No entanto, continua-se com a amamentação até o segundo ano de vida ou mais, a depender da nutriz, prática que contribuirá para a diminuição dos índices de morbimortalidade infantil(13). Conforme vemos a seguir, a falta de orientação e de apoio determina na mulher um sofrimento físico que poderia ser evitado com medidas educativas.

"Ela suga bem, mama bem. Ela sempre mamou assim, aí quando eu vim no Clubinho do Bebê, eles viram que ela pegava bem direitinho." (E4)

"Até os 6 meses amamentei, mas agora ela já está comendo. Amamentei os meus outros dois filhos até 2 anos e ainda estou amamentando ela." (E5)

"Ela já está comendo papinha e frutas desde os 6 meses, mas antes era só peito." (E6)

"...já está comendo papinha, comecei a dar com 6 meses..." (E8)

Observa-se que houve desmame precoce, pois a mãe já está introduzindo papinha e frutas durante os 6 meses de idade de seu bebê.

A maioria das entrevistadas não tinha trabalho formal, o que facilitou o AME. Por outro lado, alguns autores referem que o trabalho materno só não é empecilho se houver condições favoráveis à manutenção do aleitamento, como, por exemplo, respeito à licença-gestante, creche ou condições para o aleitamento no local e horário do trabalho. Percebemos que as mães que exerciam alguma ocupação 
não possuíam carteira de trabalho assinada, portanto não usufruíram o direito de licença à maternidade, dificultando assim o aleitamento materno exclusivo.

"...A minha amamentação não foi exclusiva, ela já tomava NAM desde os 4 meses, porque eu estou trabalhando, né..., mas eu não tiro o peito e elajá está comendo frutas e papinhas." (E3) Estudos revelaram que o trabalho é um elemento dificultante ou impeditivo para a amamentação ${ }^{(14)}$.

\section{CONSIDERAÇÕES FINAIS}

O estudo confirmou que os motivos pelos quais as mães deixam de amamentar seus filhos condizem com o que a literatura afirma, evidenciando que os saberes maternos transmitidos pela cultura familiar (de mãe para filha) são fator determinante para dar continuidade. Percebemos que o conhecimento das mães sobre aleitamento materno construído a partir das orientações fornecidas no alojamento conjunto influenciou nessa prática. Reconhecemos que há interferência da escolaridade na manutenção do aleitamento materno e a compreensão sobre o que é aleitamento materno exclusivo. $O$ aleitamento materno e a amamentação são momentos que precisam de uma intervenção integrada às necessidades de saúde da mulher da criança e da família, no trabalho, enfim, na rede social em que essa mulher está inserida, mas não somente sob determinado aspecto biológico ou pediátrico, e sim como um processo social, culturalmente implicado tanto na saúde da mulher e da criança quanto no andar da vida em si.

\section{Referências}

1. Organização Mundial de Saúde. Estratégia global para alimentação lactentes e crianças de primeira infância. São Paulo: IBFAN Brasil; 2005. 2. Cabral VLM, Campestrini S. Mães desejosas de amamentar enfrentam despreparo profissional. Programa de Aleitamento Materno.

Rev Palma. 2003:01-03.

3. Ministério da Saúde (BR). Política Nacional de Aleitamento Materno, 2004 [Internet]. [citado em 2008 Out 30]. Disponível em:

http://www.saude.gov.br.

4. Oliveira RL, Silva AN. Aspectos legais do aleitamento materno:

cumprimento da lei por hospitais de médio e de grande porte de Maceió. Rev Bras Saúde Matern Infant. 2003;3(1):43-4.

5. Giugliani ERJ, Lamounier JA. Aleitamento materno: uma contribuição científica para a prática do profissional de saúde. J Pediatr (Rio de Janeiro). 2008;80(5):117-8.

6. Primo CC, Caeano LC. A decisão de amamentar da nutriz: percepção de sua mãe. J Pediatr (Rio de Janeiro). 1999;75(6):449-55.

7. Weigert EM. Influência da técnica de amamentação nas frequências de aleitamento materno exclusivo e lesões mamilares no primeiro mês de lactação. J Pediatr (Rio de Janeiro). 2005;81(05):304-10.
8. Silva IA. Enfermagem e aleitamento materno: combinando práticas seculares. Rev Esc Enferm USP. 2000;34(4):362-9.

9. Ministério da Saúde (BR). Glossário do Ministério da Saúde: projeto de terminologia em saúde. Brasília: Ministério da Saúde; 2004.

(Série cadernos técnicos. Série F. Comunicação e Educação em Saúde).

10. Campos CJG. Método de análise de conteúdo: ferramenta para a análise de dados qualitativos no campo da saúde. Rev Bras Enferm. 2004;57(5):611-4.

11. Percegoni N. Conhecimento sobre aleitamento materno de puérperas atendidas em dois hospitais de Viçosa, Minas Gerais. Rev Nutr. 2002; 15(1):29-35

12. Montrone AVG. Promoção da amamentação por crianças do Ensino Fundamental. Interface Comun Saúde Educ. 2008.

13. Teixeira MA. Significados de avós sobre a prática do aleitamento materno no cotidiano familiar: a cultura do querer-poder amamentar. Texto Contexto Enferm. 2006;15(1):98-106.

14. Almeida NA, Cleide G. Aleitamento materno: uma abordagem sobre o papel do enfermeiro no pós-parto. Rev Eletrônica Enferm. 2004;6(3):358-67. 